$05,11,13$

\title{
Магнитокалорический эффект в окрестности температуры магнитной компенсации аморфных ферримагнитных пленок Gd-Co
}

\author{
(C) А.В. Свалов ${ }^{1}$, А.В. Архипов ${ }^{1}$, В.Н. Лепаловский ${ }^{1}$, Е.А. Степанова ${ }^{1}$, \\ В.О. Васьковский ${ }^{1,2}$, Г.В. Курляндская ${ }^{1}$ \\ ${ }^{1}$ Институт естественных наук и математики, \\ Уральский федеральный университет им. Б.Н. Ельцина, \\ Екатеринбург, Россия \\ ${ }^{2}$ Институт фризики металлов им. М.Н. Михеева РАН, \\ Екатеринбург, Россия \\ E-mail: andrey.svalov@urfu.ru
}

Поступила в Редакцию 9 апреля 2021 г.

В окончательной редакции 9 апреля 2021 г.

Принята к публикации 19 апреля 2021 г.

\begin{abstract}
Представлены результаты исследования магнитных и магнитокалорических свойств аморфных ферримагнитных пленок $\mathrm{Gd}-\mathrm{Co}$, обладающих перпендикулярной магнитной анизотропией, в широком диапазоне полей и температур. Смена знака магнитокалорического эффекта вблизи температуры компенсации происходит почти скачкообразно при ориентации магнитного поля перпендикулярно плоскости пленки и в некотором интервале температур при ориентации поля вдоль плоскости образца. Наиболее вероятной причиной размытия этого перехода является возникновение неколлинеарной магнитной структуры.
\end{abstract}

Ключевые слова: ферримагнетизм, аморфные пленки, магнитокалорический эффект, магнитная компенсация.

DOI: 10.21883/FTT.2021.09.51308.28H

\section{1. Введение}

Магнитокалорический эффект (МКЭ) продолжает оставаться объектом интенсивных исследований как с точки зрения разработки устройств экологически чистого магнитного охлаждения, так и фундаментальных исследований магнитной энтропии и особенностей магнитных фазовых переходов. Ферримагнитные материалы находятся в русле этого внимания $[1,2]$. При этом, количество публикаций, посвященных исследованию МКЭ в ферримагнетиках вблизи состояния магнитной компенсации, весьма невелико, хотя именно в таких материалах наблюдается очень интересное явление - смена знака МКЭ [3,4]. В последние годы также отмечается рост интереса к изучению МКЭ в наноструктурах, таких как тонкие пленки и многослойные пленочные системы [5,6-8]. Это связано с возможностью использовать пленки как модельный объект [9] и перспективами их применения в устройствах охлаждения элементов микроэлектроники [10]. Пленки $\mathrm{Gd}-\mathrm{Co}$ при определенных условиях могут обладать перпендикулярной магнитной анизотропией $[11,12]$, что увеличивает их привлекательность как модельного объекта. В настоящей работе представлены результаты исследования магнитных свойств и особенностей МКЭ аморфных ферримагнитных пленок $\mathrm{Gd}-\mathrm{Co}$ в окрестности температуры магнитной компенсации.

\section{2. Методика исследований}

Пленки $\mathrm{Gd}-\mathrm{Co}$ толщиной $40 \mathrm{~nm}$ были получены на стеклянных подложках методом магнетронного сораспыления мишеней Сo и $\mathrm{Gd}$ в атмосфере аргона. Пленки содержали $\sim 19.8$ at.\% Gd, состав образцов определялся с помощью ренгенофлуоресцентного спектрометpa Nanohunter. Для предотвращения окисления пленки $\mathrm{Gd}-\mathrm{Co}$ были защищены буферным и покрывающим слоями Та толщиной $5 \mathrm{~nm}$. Выборочная рентгеновская дифрактометрия образцов идентифицировала их структурное состояние как рентгеноаморфное. Магнитные свойства пленок были исследованы с помощью измерительного комплекса MPMS-7XL. Температурные зависимости изменения магнитной части энтропии пленок $\Delta S_{M}(T, H)$ были получены с помощью соотношения Максвелла на основе изотермических зависимостей намагниченности, измеренных в полях до $70 \mathrm{kOe}$

$$
\Delta S_{M}=\int_{0}^{H}\left(\frac{\partial M}{\partial T}\right)_{H} d H,
$$

где $M-$ намагниченность, $H-$ магнитное поле, $T-$ температура.

\section{3. Полученные результаты}

Температурная зависимость спонтанной намагниченности $M(T)$ пленки $\operatorname{Gd}_{19.8} \mathrm{Co}_{80.2}$ имеет характерный 


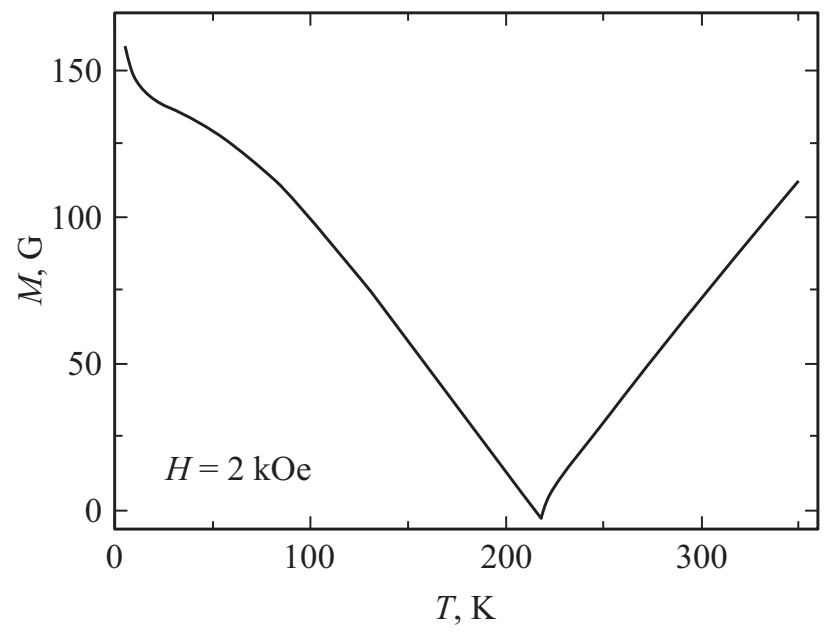

Рис. 1. Температурная зависимость намагниченности пленки $\mathrm{Gd}_{19.8} \mathrm{Co}_{80.2}$.

для ферримагнетиков минимум вблизи температуры компенсации $T_{\text {comp }} \approx 215 \mathrm{~K}$ (рис. 1 ). Его существование обусловлено антиферромагнитным характером обменного взаимодействия магнитных моментов подрешеток редкоземельного элемента (Р3) и переходного металла (ПМ), а также различной температурной зависимостью этих моментов $[11,12]$. При $T<T_{\text {сотр в суммарном }}$ магнитном моменте пленки доминирует момент Р3 компоненты, именно он выстраивается вдоль внешнего магнитного поля. При $T>T_{\text {comp }}$, напротив, преобладает магнитный момент Co, а момент Gd оказывается ориентирован против направления внешнего магнитного поля. Отметим также, что острота минимума на зависимости $M(T)$ свидетельствует о высокой степени однородности образца по химическому составу [13].

На рис. 2 показаны в качестве примера петли гистерезиса, измеренные на пленке $\mathrm{Gd}-\mathrm{Co}$ при разных температурах при ориентации внешнего магнитного поля как в плоскости, так и перпендикулярно плоскости образца. Они свидетельствуют о том, что во всем исследованном температурном интервале пленка обладала перпендикулярной магнитной анизотропией, то есть ось легкого намагничивания (ОЛН) совпадала с нормалью к плоскости пленки.

На рис. 3 представлены температурные зависимости изменения магнитной части энтропии $\Delta S_{M}$ пленки $\mathrm{Gd}-\mathrm{Co}$, полученные на основе изотермических зависимостей намагниченности, измеренных при ориентации поля как в плоскости, так и перпендикулярно плоскости образца. Видно, что в обоих случаях знак $\Delta S_{M}$

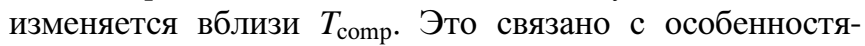
ми температурной зависимости $M(T)$. Как следует из выражения (1), отрицательная производная намагниченности по температуре определяет отрицательный знак $\Delta S_{M}$, т.е. образец нагревается при приложении внешнего магнитного поля. Такая ситуация реализуется при

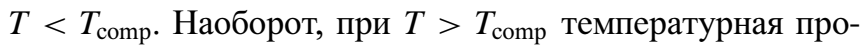

изводная намагниченности положительна, следовательно, $\Delta S_{M}>0$, и образец охлаждается при адиабатическом приложении внешнего магнитного поля (так называемый обратный МКЭ).

Подобная смена знака МКЭ наблюдалась ранее в объемных образцах ферримагнитных соединений

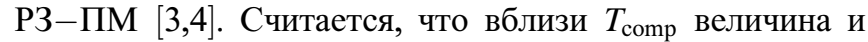
знак $\Delta S_{M}$ определяются, в основном, Р3-подрешеткой, так как намагниченность ПМ подрешетки практически не меняется в этом температурном интервале [14]. Расчет температурных зависимостей намагниченностей подрешеток Gd и Со в наших пленках $\mathrm{Gd}-\mathrm{Co}$, проведенный в рамках феноменологической теории коллине-
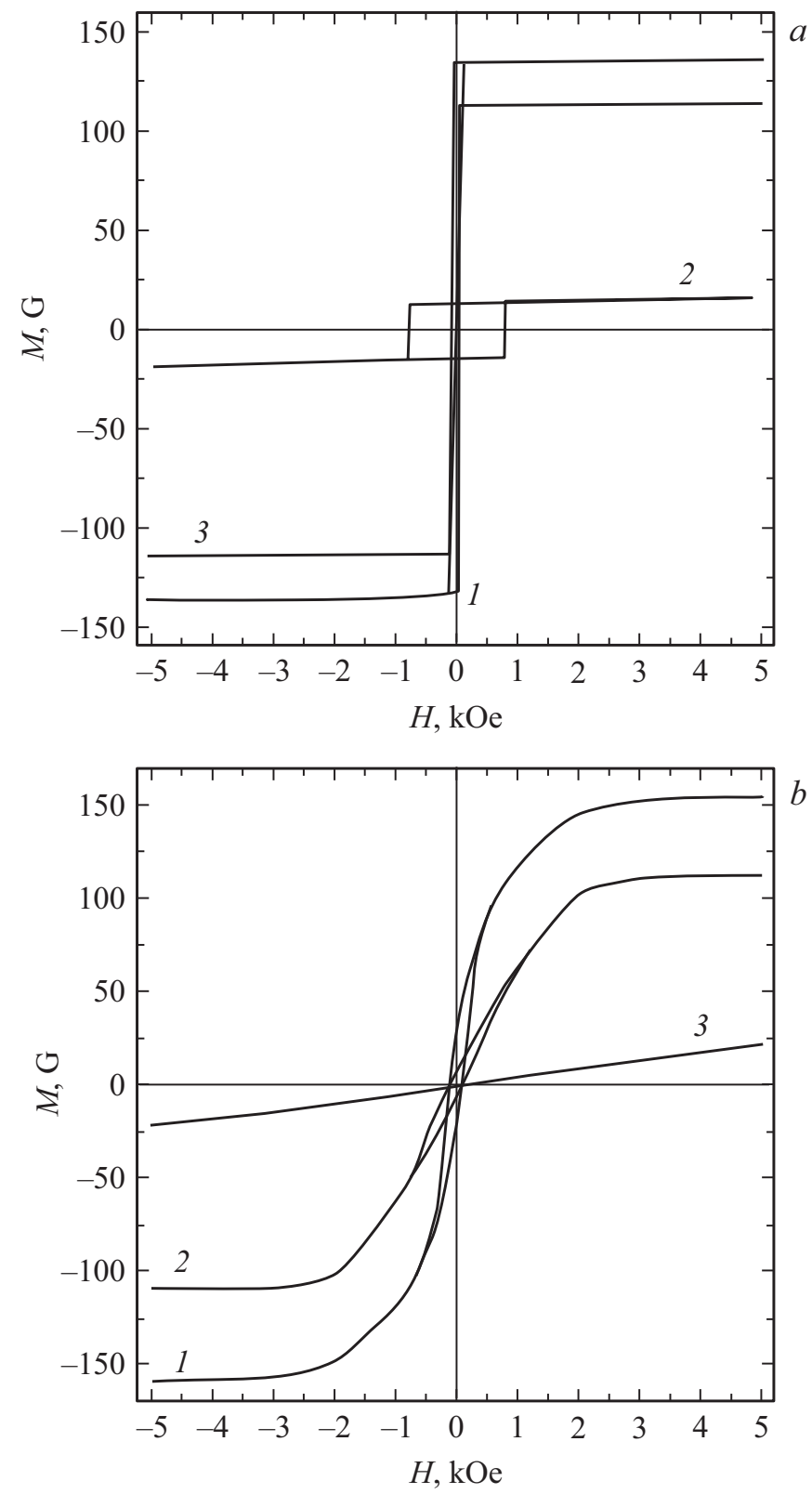

Рис. 2. Петли гистерезиса, измеренные при ориентации внешнего поля перпендикулярно $(a)$ и вдоль плоскости $(b)$ образца при температуре $5 \mathrm{~K}(1), 200 \mathrm{~K}$ (2) и $350 \mathrm{~K}$ (3). 

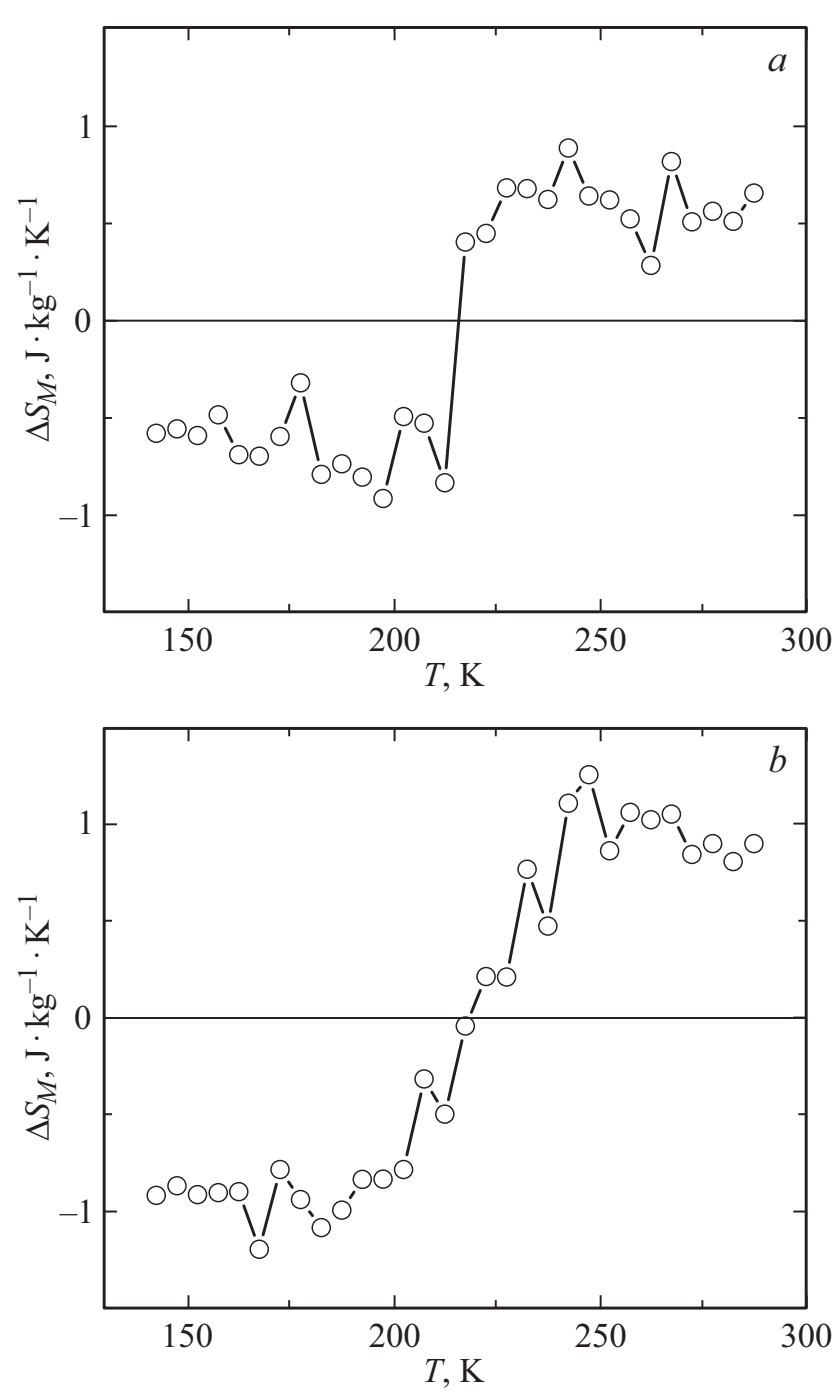

Рис. 3. Температурные изменения магнитной части энтропии пленки $\mathrm{Gd}_{19.8} \mathrm{Co}_{80.2}$, полученные при ориентации магнитного поля перпендикулярно $(a)$ и вдоль плоскости $(b)$ образца.

арного ферримагнетизма Нееля, основанной на теории молекулярного поля, показал, что в исследованных образцах намагниченность подрешетки Со слабо меняется в окрестности $T_{\text {comp }}[12]$, поэтому особенности МКЭ в пленках $\mathrm{Gd}-$ Со в данном температурном интервале также обусловлены подрешеткой Gd.

Величина МКЭ в исследованных пленках вблизи

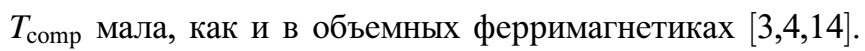
Обусловлено это как малой скоростью изменения намагниченности образца при изменении температуры, так и меньшим откликом на внешнее магнитное поле в отличие от ситуации вблизи температуры Кюри.

Малость сигнала от образца, особенно вблизи $T_{\text {comp, }}$ является причиной разброса значений $\Delta S_{M}$ на зависимости $\Delta S_{M}(T)$. Однако отчетливо просматривается тенденция, что при ориентации поля перпендикулярно плоскости пленки (вдоль ОЛН) смена знака $\Delta S_{M}$ происходит в довольно узком температурном интервале, близко к скачкообразному поведению, при пересечении $T_{\text {comp }}$ (рис. $3, a$ ), в то время как при ориентации поля в плоскости образца этот переход плавно растянут по температуре (рис. $3, b$ ). Теория предсказывает скачкообразное изменение знака $\Delta S_{M}$ при $T=T_{\text {comp }}$ [15]. Имеющиеся в литературе данные показывают, что на эксперименте для объемных ферримагнетиков изменение знака $\Delta S_{M}$ происходит в некотором интервале температур $[3,4,14]$. В качестве возможной причины этого, как правило, рассматриваются нарушение структурного порядка и связанная с ним флуктуация обменного взаимодействия или возникновение неколлинеарной магнитной структуры под воздействием внешнего магнитного поля $[16,17]$. В нашем случае вероятны оба сценария. В аморфных пленках отсутствует структурный порядок, но флуктуации обменного взаимодействия могут быть обусловлены локальными флуктуациями химического состава, которые, как известно, существуют в аморфных ферримагнитных пленках Р3-ПМ $[18,19]$. Однако различающиеся зависимости $\Delta S_{M}(\mathrm{~T})$, представленные на рис. 3, получены на одном и том же образце, это заставляет отказаться от предположения, что основной причиной протяженного изменения знака $\Delta S_{M}$ при ориентации поля в плоскости пленки является объемная флуктуация обменного взаимодействия в образце. В кристаллических соединениях Р3-ПМ, аналогах наших аморфных пленок $\mathrm{Gd}-\mathrm{Co}$, величина критического магнитного поля, требуемого для индуцирования неколлинеарной магнитной структуры, измеряется сотнями

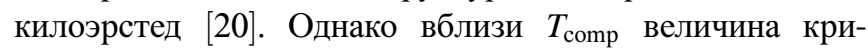
тического поля сильно уменьшается $[21,22]$. Подобное уменьшение критического поля можно ожидать и для исследованных пленок, тем более что так называемый „размерный фактор“ снижает общую магнитную связь в образце, находящемся в тонкопленочном состоянии [23].

На рис. 4 представлены температурные зависимости намагниченности, измеренные в поле разной напряженности и при ориентации поля как перпендикулярно плоскости образца, т.е. вдоль ОЛН, так и в плоскости образца.

При ориентации поля вдоль ОЛН и его напряженности до $20 \mathrm{kOe}$ на зависимости $M(T)$ наблюдается острый минимум при $T=T_{\text {comp, }}$ а при $H \geq 30 \mathrm{kOe}$ данный минимум „размывается“, и величина $M$ не достигает нуля (рис. 4, $a$ ), что является следствием нарушения антипараллельного упорядочения магнитных моментов подрешеток Со и $\mathrm{Gd}$ и возникновения неколлинеарной магнитной структуры в сильном магнитном поле. При ориентации поля вдоль плоскости пленки размытие минимума на зависимости $M(T)$ наблюдается уже при $H=10 \mathrm{kOe}$ (рис. $4, b$ ), т.е. вероятность возникновения неколлинеарной структуры ожидаемо [21,22] выше при ориентации внешнего поля перпендикулярно ОЛН. Для большей наглядности на рис. 5 приведены зависимости $M(T)$, измеренные при ориентации магнитного поля как перпендикулярно, так и вдоль плоскости образца. 

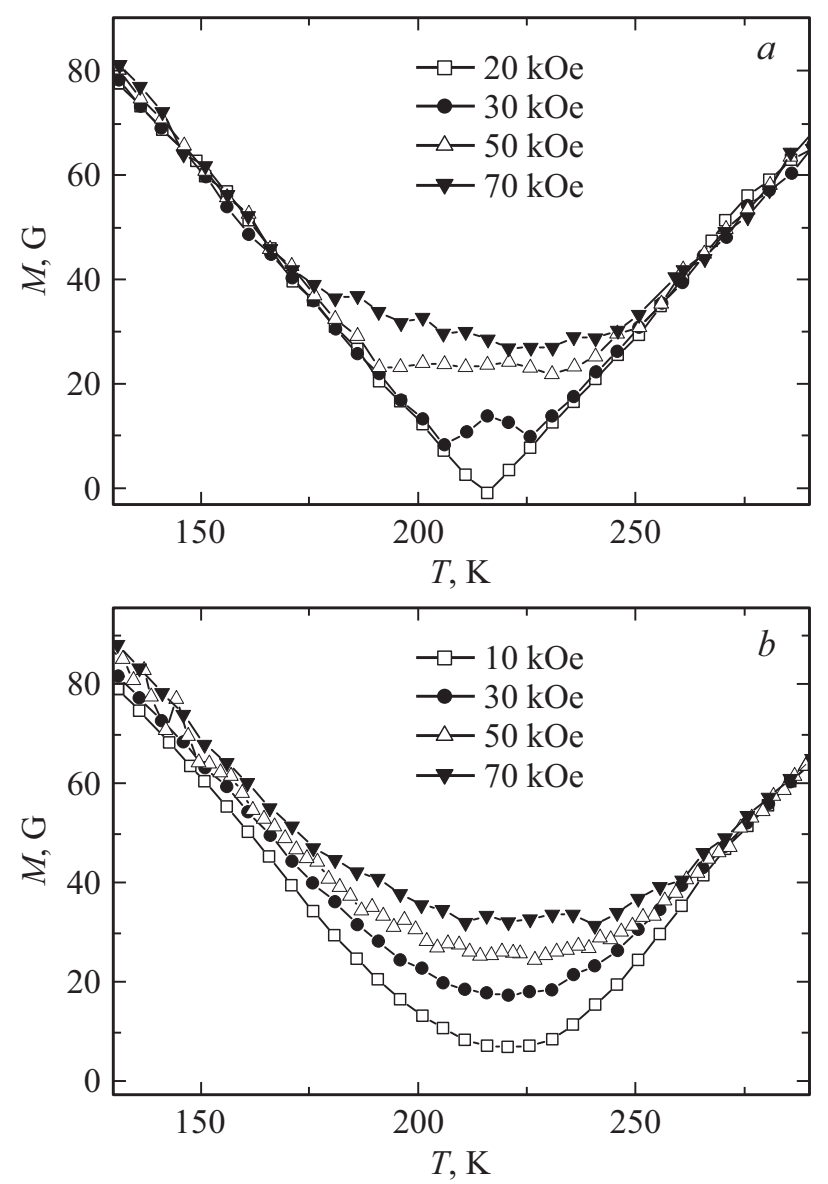

Рис. 4. Температурные зависимости намагниченности пленки $\mathrm{Gd}_{19.8} \mathrm{Co}_{80.2}$, измеренные при ориентации магнитного поля перпендикулярно $(a)$ и вдоль плоскости $(b)$ образца.

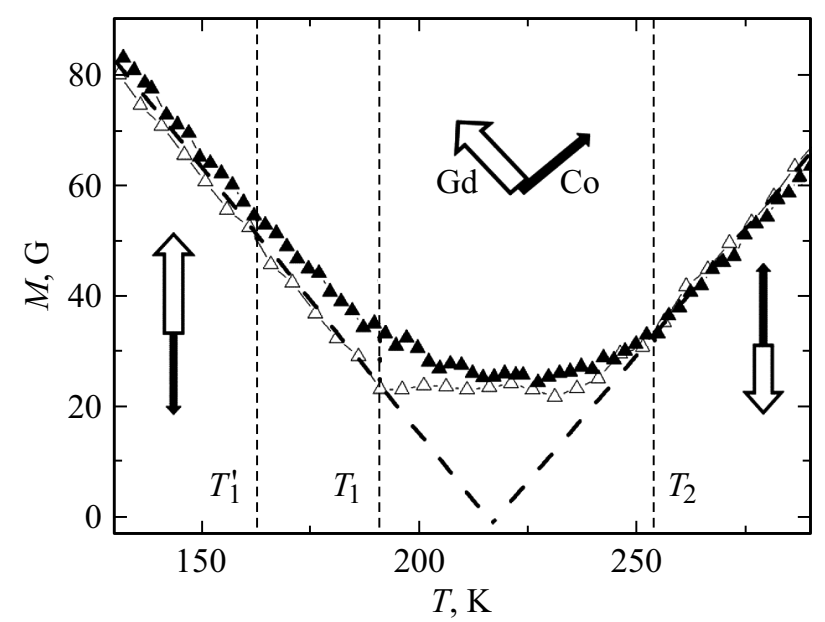

Рис. 5. Температурные зависимости намагниченности пленки $\mathrm{Gd}_{19.8} \mathrm{Co}_{80.2}$, измеренные при ориентации магнитного поля перпендикулярно (открытые символы) и вдоль плоскости образца (заполненные символы). $H=50 \mathrm{kOe}$.

При ориентации поля вдоль ОЛН в температурных интервалах ниже $T_{1}$ и выше $T_{2}$ наблюдается линейный ход зависимости $M(T)$, что характерно для однородных ферримагнитных пленок Р3-ПМ [12,13,22] при антипа- раллельной выстроенности намагниченностей подрешеток Р3 и ПМ. В температурном интервале между $T_{1}$ и $T_{2}$ под воздействием внешнего магнитного поля возникает неколлинеарная магнитная структура. При ориентации поля в плоскости образца (перпендикулярно ОЛН) наблюдается аналогичная ситуация, однако, если величины $T_{2}$ для двух ориентаций поля практически совпадают, то нижняя граница возникновения неколлинеарной магнитной структуры при плоскостной ориентации поля заметно отличается $\left(T_{1}^{\prime}<T_{1}\right)$. Подобный фазовый переход и зависимость температурного интервала существования неколлинеарной магнитной структуры от взаимной ориентации поля и ОЛН ранее наблюдался в аморфных ферримагнитных пленках Dy-Co [22]. Таким образом, возникновение неколлинеарной магнитной структуры под воздействием внешнего магнитного поля представляется более вероятной причиной протяженного по температуре изменения знака $\Delta S_{M}$. Кроме того, в ходе дальнейших исследований необходимо рассмотреть роль компоненты МКЭ, связанной с магнитной анизотропией пленок [24,25].

\section{4. Заключение}

Установлено, что особенности магнитокалорического эффекта в тонкопленочном ферримагнетике во многом аналогичны особенностям, наблюдаемым в объемных объектах. В частности, вблизи температуры компенсации происходит смена знака изменения магнитной части энтропии $\Delta S_{M}(T)$, которая обусловлена температурным поведением намагниченности редкоземельной подрешетки. При ориентации поля перпендикулярно плоскости пленки смена знака $\Delta S_{M}$ происходит практически скачкообразно при пересечении $T_{\text {comp, }}$ в то время как при ориентации поля в плоскости образца этот переход растянут внутри некоторого температурного интервала. Наиболее вероятной причиной размытия перехода является возникновение неколлинеарной магнитной структуры.

\section{Финансирование работы}

Работа выполнена при финансовой поддержке РНФ в рамках научного проекта № 18-72-10044.

\section{Конфликт интересов}

Авторы заявляют, что у них нет конфликта интересов.

\section{Список литературы}

[1] Z.W. Wang, P. Yu, Y.T. Cui, L. Xia. J. Alloy Compd. 658, 598 (2016).

[2] M. Tadout, C.-H. Lambert, M.S. El Hadri, O. Mounkachi, A. Benyoussef, M. Hamedoun, M. Benaissa, S. Mangin. J. Appl. Phys. 123, 053902 (2018). 
[3] К.П. Белов, Е.В. Талалаева, Л.А. Черникова, А.С. Андреенко, В.И. Ивановский. ЖЭТФ 66, 655 (1974).

[4] S.A. Nikitin, N.Yu. Pankratov, A.I. Smarzhevskaya, J. Ćwik, Yu.S. Koshkid'ko, A.Yu. Karpenkov, D.Yu. Karpenkov, Yu.G. Pastushenkov, K. Nenkov, K. Rogacki. J. Alloys Compd. 854, 156214 (2021).

[5] A.V. Svalov, V.O. Vas'kovskiy, J.M. Barandiaran, K.G. Balymov, I. Orue, G.V. Kurlyandskaya. Phys. Status Solidi A 208, 2273 (2011).

[6] А.А. Фраерман, И.А. Шерешевский. Письма в ЖЭТФ 101, 693 (2015).

[7] М.А. Кузнецов, А.Б. Дровосеков, А.А. Фраерман. ЖЭТФ 159, 95 (2021).

[8] А.А. Фраерман. Письма в ЖЭТФ 113, 353 (2021).

[9] D. Doblas, L.M. Moreno-Ramírez, V. Franco, A. Conde, A.V. Svalov, G.V. Kurlyandskaya. Mater. Design 114, 214 (2017).

[10] R. Niemann, O. Heczko, L. Schultz, S. Fähler. Appl. Phys. Lett. 97, 222507 (2010).

[11] P. Chaudhari, J.J. Cuomo, R.J. Gambino. Appl. Phys. Lett. 22, 337 (1973).

[12] В.О. Васьковский, А.Н. Горьковенко, О.А. Аданакова, А.В. Свалов, Н.А. Кулеш, Е.А. Степанова, Е.В. Кудюков, В.Н. Лепаловский. ФММ 120, 1151 (2019).

[13] В.О. Васьковский, В.В. Лесных, Г.С. Кандаурова, Т.Х. Агамальян. ФММ 59, 470 (1985).

[14] Н.Ю. Панкратов, Т.П. Каминская, И.С. Терешина, А.А. Макуренкова, А.Ю. Карпенков, М.А. Пауков, С.А. Никитин. ФTT 62, 719 (2020).

[15] P.J. von Ranke, B.P. Alho, E.J.R. Plaza, A.M.G. Carvalho, V.S.R. de Sousa, N.A. de Oliveira. J. Appl. Phys. 106, 053914 (2009).

[16] E. Burzo, I. Balasz, I. Deac, R. Tetean. J. Magn. Magn. Mater. 322, 1109 (2010).

[17] С.А. Никитин, Е.В. Талалаева, Л.А. Черникова, А.С. Андреенко. ЖЭТФ 65, 2058 (1974).

[18] T.-M. Liu, T. Wang, A.H. Reid et al. Nano Lett. 15, 6862 (2015).

[19] E. Kirk, C. Bull, S. Finizio, H. Sepehri-Amin, S. Wintz, A.K. Suszka, N.S. Bingham, P. Warnicke, K. Hono, P.W. Nutter, J. Raabe, G. Hrkac, T. Thomson, L.J. Heyderman. Phys. Rev. Mater. 4, 074403 (2020).

[20] Yu. Skourskia, M.D. Kuz'min, K.P. Skokov, M. Richter, D. Eckert, I.S. Tereshina, K.-H. Müller. J. Magn. Magn. Mater. 290-291, 435 (2005).

[21] К.П. Белов, А.К. Звездин, А.М. Кадомцева, Р.З. Левитин. Ориентационные переходы в редкоземельных магнетиках. Наука, М. (1979). 317 с.

[22] Б.П. Хрусталев, В.Г. Поздняков, Г.И. Фролов. ФТТ 35, 921 (1993).

[23] A.V. Svalov, V.O. Vas'kovskiy, G.V. Kurlyandskaya. Phys. Met. Metallogr. 118, 1263 (2017).

[24] Е.П. Найден, С.М. Жиляков. ФТТ 39, 1078 (1997).

[25] S.A. Nikitin, K.P. Skokov, Yu.S. Koshkid'ko, Yu.G. Pastushenkov, T.I. Ivanova. Phys. Rev. Lett. 105, 137205 (2010).

Редактор К.В. Емцев 